Journal of Advanced Research in Fluid Mechanics and Thermal Sciences

\title{
Effect of Internal Diameter and Working Fluids on Thermal Performance of a Vertical Closed-Loop Oscillating Heat Pipe with Double Heat Sources
}

\author{
Poomin Krisangsri ${ }^{1{ }^{*}}$, Teerasak Hudakorn ${ }^{1}$, Noppong Sritrakul ${ }^{1}$ \\ 1 Department of Mechanical Engineering, Faculty of Engineering and Industrial Technology, Silpakorn University, Nakhon Pathom, 73000, \\ Thailand
}

\section{ARTICLE INFO}

\section{Article history:}

Received 6 February 2021

Received in revised form 30 March 2021

Accepted 1 April 2021

Available online 9 May 2021

\section{Keywords:}

Thermal performance; Vertical closedloop oscillating heat pipe with double heat sources; Latent heat of evaporation; Heat flux; Thermal resistance

\section{ABSTRACT}

This research investigates the effects of internal diameter and working fluids on the thermal performance of a vertical closed-loop oscillating heat pipe with double heat sources (VCLOHP w/DHS). The closed-loop oscillating heat pipe (CLOHP) tested was made of a copper capillary tube with various inner diameters and working fluids. Two evaporator sections in the outer end of CLOHP were heated by a Ni-Cr alloy resistance wire heater. The heat was removed from the condenser section in the middle of CLOHP by forced convection heat transfer of ambient air blowing the section. The results showed that, for the inner diameters of 1.5 and $2.0 \mathrm{~mm}$, the thermal resistance decreased when the inner diameter and the latent heat of evaporation increased.

\section{Introduction}

A heat pipe is a heat transfer device that relocates thermal energy through cycles of vaporization and condensation. The heat pipe is widely used in laptops, mobile phones, and tablets. Oscillating heat pipes (OHPs) were first introduced by Akachi et al., [1] in 1996. The OHP differ from conventional heat pipes in design and working principle. The OHP is made of a long capillary tube bent into an undulating bundle. The inner diameter of the OHP must be smaller than the critical inner diameter to allow the working fluid to arrange in slug-train units, forming vapor plugs and liquid slugs along the entire length of the tube due to the effect of surface tension [2,3]. Generally, OHPs can be divided into three groups: closed-end oscillating heat pipe (CEOHP), closed-loop oscillating heat pipe (CLOHP), and closed-loop oscillating heat pipe with check valve (CLOHP/CV). CLOHP has higher thermal performance than CEOHP and is constructed easier than CLOHP/CV. Therefore, this study focuses on CLOHP. The structure of the ordinary CLOHP is shown in Figure 1(a).

Nowadays, designs and applications of CLOHP for transferring heat from various sources are simple. Previous studies showed that CLOHP thermal performance depended on various parameters

\footnotetext{
* Corresponding author.

E-mail address: pookado-4@hotmail.com
}

https://doi.org/10.37934/arfmts.82.2.120126 
including inner diameter, evaporator section lengths, filling ratio, working fluid properties, number of turns, and orientation of operation [4-16].

Ordinary CLOHP is used with one heat source and releases heat to the heat sink. To utilize more than one heat source of electronic equipment, the ordinary CLOHP has been redesigned. The new design of CLOHP can simultaneously receive heat from two heat sources at the outer ends and release that heat to the middle section. The new design has been named as "closed-loop oscillating heat pipe with double heat sources" (CLOHP w/DHS) as shown in Figure 1.

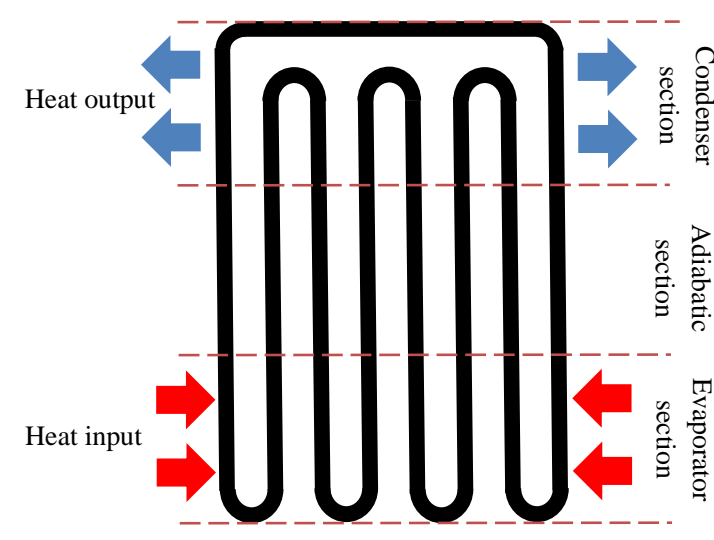

(a)

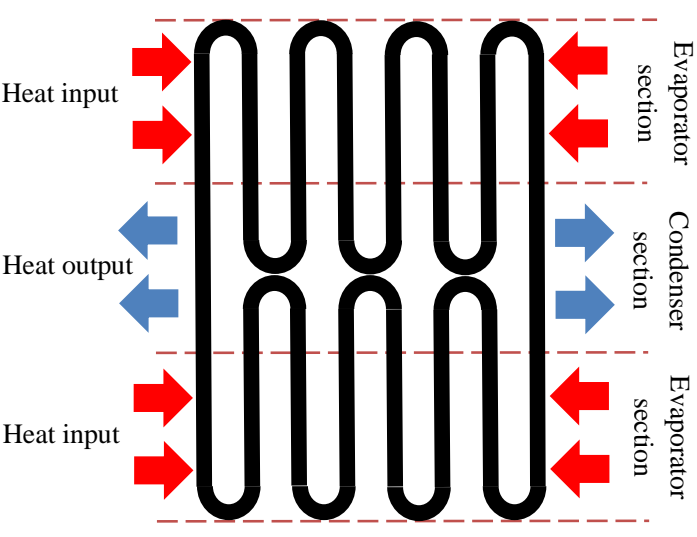

(b)

Fig. 1. (a) Ordinary CLOHP; (b) CLOHP w/DHS

The research about CLOHP w/DHS has not been reported yet. Therefore, this work is the first study to investigates the thermal performance of the vertical closed-loop oscillating heat pipe with double heat sources (VCLOHP w/DHS). The effects of inner diameters and properties of working fluids on the thermal performance were examined.

\section{Methodology}

The experimental setup, as shown in Figure 2, consisted of VCLOHP w/DHS made of long copper capillary tubes with inner diameters of $1.0,1.5$, and $2.0 \mathrm{~mm}$, bent into 16 turns along a meandering length. Both ends were connected to form a loop. Two evaporator sections were located at the outer end of the bundle, while one condenser section was placed on the middle of the VCLOHP w/DHS with no adiabatic section. The lengths of evaporator and condenser sections were the same at $50 \mathrm{~mm}$. R123, ethanol, and water were used as working fluids with a filling ratio of $50 \%$ by volume. Two heat sources were installed along the longitudinal axis of the evaporator section. Each heat source generated heat using two $\mathrm{Ni}-\mathrm{Cr}$ alloy resistance wire heaters with a diameter of $0.5 \mathrm{~mm}$. Evaporator temperature was controlled at $90 \pm 5^{\circ} \mathrm{C}$. Heat was removed from the condenser sections by forced convective heat transfer of blown ambient air. Air flow velocity was controlled by an AC motor (Mitsumi, F1209) and maintained at $0.3 \mathrm{~m} / \mathrm{s}$, while air temperature was kept at $25^{\circ} \mathrm{C}$. Twenty chromel-alumel thermocouples (Omega, Type $\mathrm{K}$ with $\pm 0.5^{\circ} \mathrm{C}$ accuracy) were used to measure the temperatures of the evaporator and condenser sections of the VCLOHP w/DHS and the ambient air temperature at the inlet and outlet of the condenser section. All temperature data were monitored by a temperature recorder (Graphtec, GL820 with $\pm 0.1^{\circ} \mathrm{C}$ accuracy). Air velocity and relative humidity were measured by a Testo 435 ( $\pm 0.01 \mathrm{~m} / \mathrm{s}$ and $\pm 0.1 \% R H$ accuracy). 


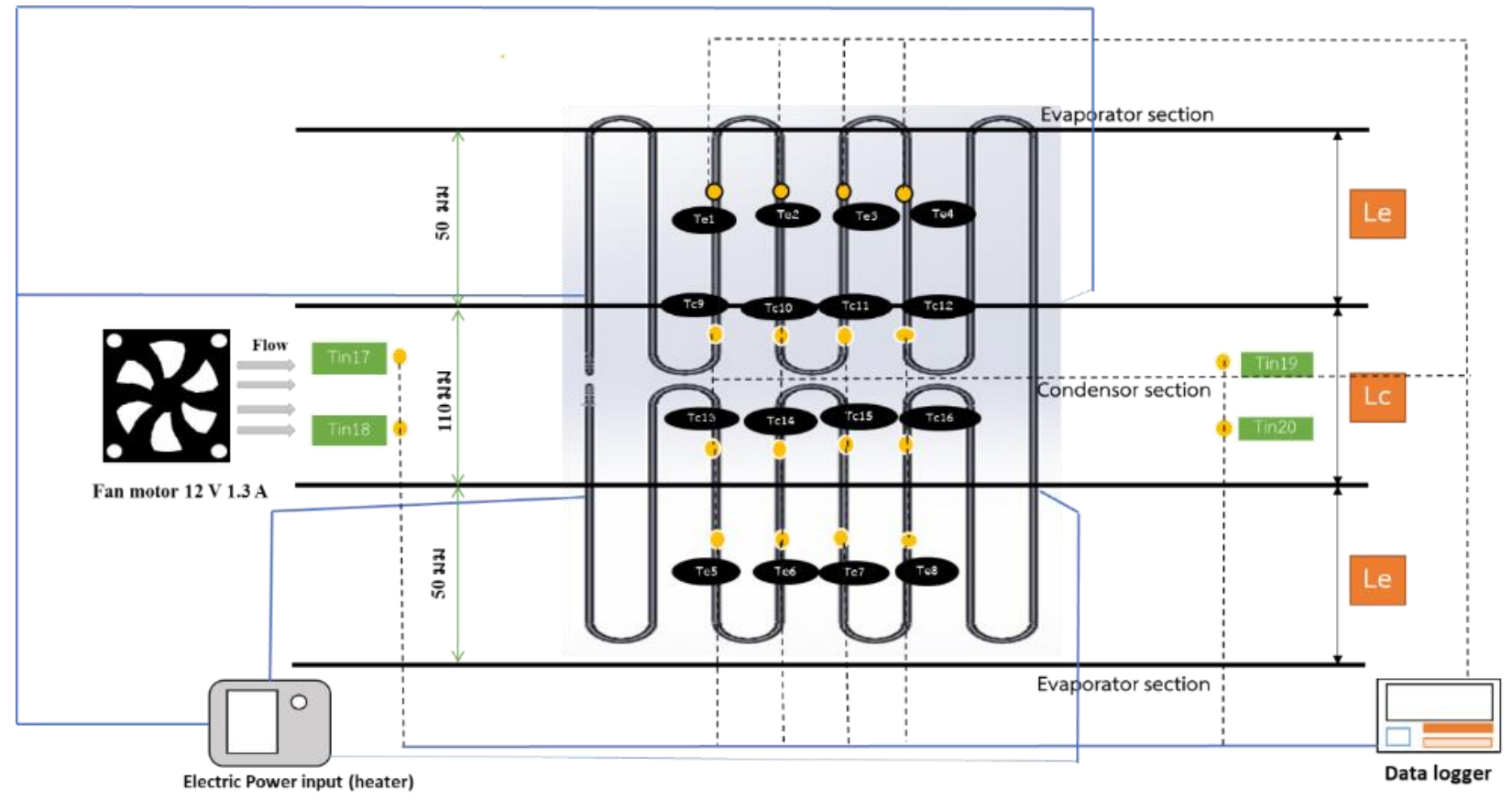

Fig. 2. Detail of experimental setup

The experiment started from turning the power controllers on. Then, heat inputs of each heat source were supplied by $\mathrm{Ni}-\mathrm{Cr}$ alloy resistance wire heaters. The temperature of evaporator section was controlled at $90 \pm 5{ }^{\circ} \mathrm{C}$. The ambient air of $25^{\circ} \mathrm{C}$ was blown through the condenser section at velocity $0.3 \mathrm{~m} / \mathrm{s}$. After a quasi-steady-state was reached, all temperatures and relative humidity were recorded. The experiment was conducted in triplicate.

Thermal performance of the VCLOHP w/DHS was evaluated by calculating the rate of heat transfer to ambient air at the condenser part and applying the conservation of energy equation for a heating process at constant specific humidity as shown in Eq. (1).

$\dot{\mathrm{q}}=\frac{\dot{\mathrm{m}}_{\text {air }}\left(\mathrm{h}_{\text {out }}-\mathrm{h}_{\text {in }}\right)}{\mathrm{A}_{\mathrm{c}}}$

where $q$ is the heat transfer rate of a VCLOHP w/DHS $\left(\mathrm{W} / \mathrm{m}^{2}\right), \dot{\mathrm{m}}_{\text {air }}$ is the mass flow rate of dry air $(\mathrm{kg} / \mathrm{s}), A_{c}$ is the inner surface area of the tube in the condenser section $\left(\mathrm{m}^{2}\right)$, and $h_{\text {in }}$ and $h_{\text {out }}$ are the enthalpies per unit mass of dry air at the inlet and outlet of the condenser section $(\mathrm{kJ} / \mathrm{kg})$, respectively.

In order to analyze the results easier, the thermal resistance per unit area was defined as "thermal resistance per unit area between the whole evaporator and condenser section" as shown in Eq. (2)

$R=\frac{T_{e, a v e}-T_{c, a v e}}{q}$

where $R$ is the thermal resistance per unit area $\left(m^{2}-K / W\right), T_{e}$,ave is the average evaporator section temperature in every heat source $(K)$ and $T_{c, \text { ave }}$ is the condenser section temperature $(K)$. 


\section{Results}

\subsection{Effects of Inner Diameters on Thermal Performance}

In this study, for all working fluids used, the inner diameters of the tube were varied from 1.0 to $2.0 \mathrm{~mm}$, which were smaller than the maximum inner diameter proposed in previous researches $[1,2]$. Figure 3(a), Figure 3(b), and Figure 3(c) show the effects of inner diameters on the heat flux and thermal resistance of the VCLOHP w/DHS using water, ethanol, and R123 as the working fluids, respectively. The inner diameter of the tube and types of working fluids used affected the thermal performance of VCLOHP w/DHS. Increase in inner diameter enhanced heat flux but decreased thermal resistance. The highest thermal performance of all VCLOHP w/DHS filled with water, ethanol, and R123 was attained at the maximum inner diameter of $2.0 \mathrm{~mm}$. With a larger inner diameter or a wider cross-sectional area of flow passage, the vapor plugs evaporate in the evaporator section and, consequently, flow towards the condenser section more continual with a higher quantity of working fluid. Thus, the CLOHP can transfer more heat; heat flux subsequently increases and thermal resistance decreases [17]. These results concurred with the studies of Charoensawan and Terdtoon [6] and Kammuang-lue et al., [17], which indicated that the thermal performance increased with larger inner tube diameter.

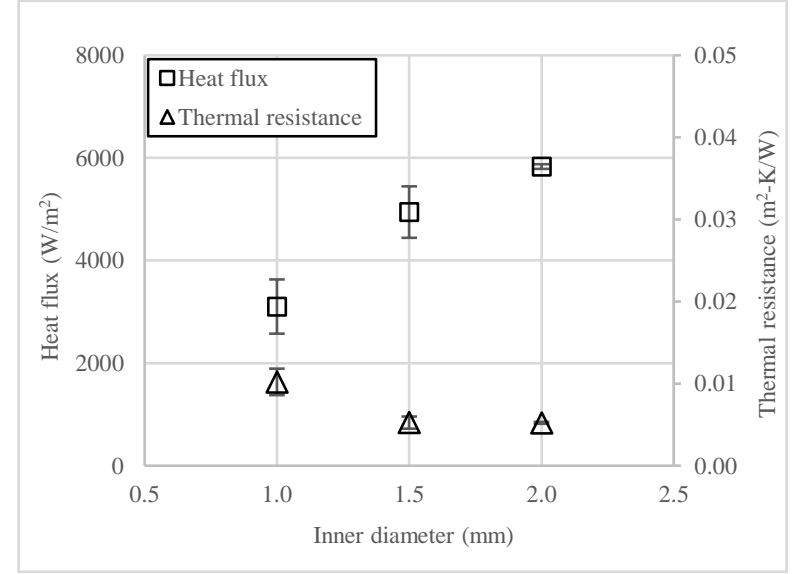

(a)

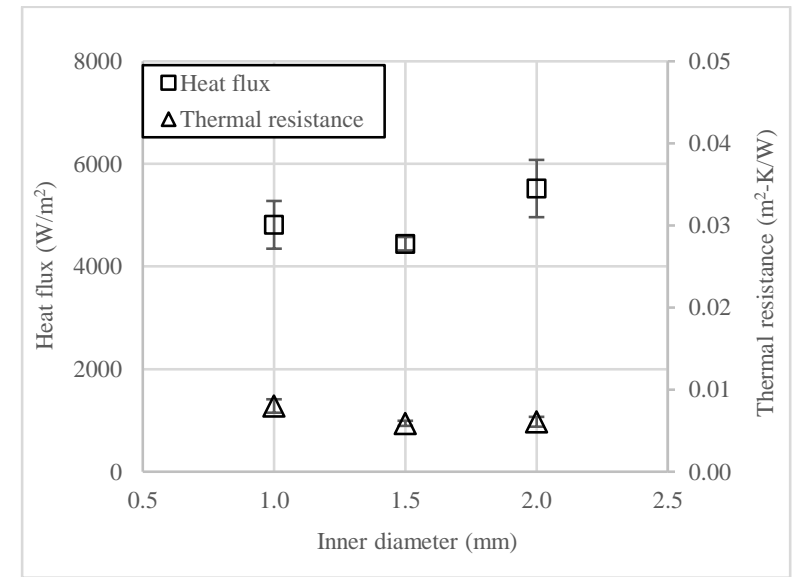

(b)

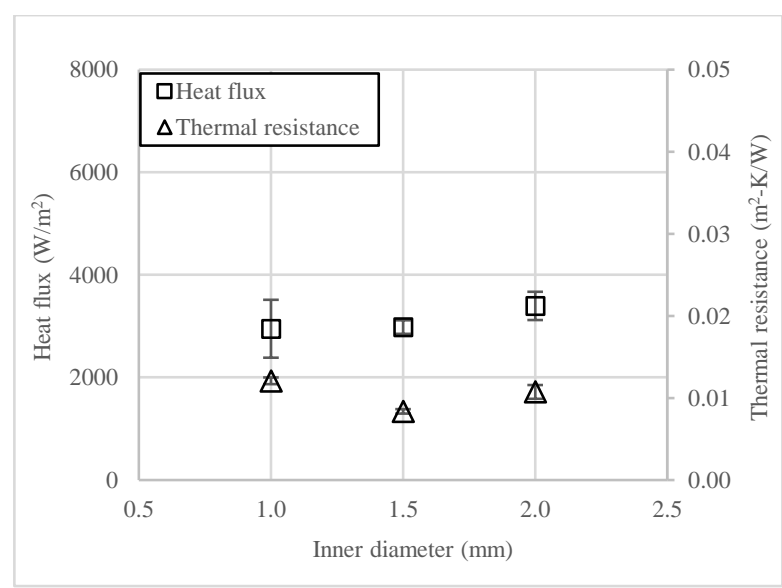

(c)

Fig. 3. Effects of inner diameters; (a) Water as working fluid, (b) Ethanol as working fluid, (c) R123 as working fluid 


\subsection{Effects of Working Fluids on Thermal Performance}

Thermodynamic properties of working fluids include latent heat of evaporation, specific heat, surface tension, viscosity, and thermal conductivity. The latent heat of evaporation is an important parameter for identifying the differences between the working fluids because the CLOHP transfers heat by evaporation and condensation mechanisms. Figure 4(a) and Figure 4(b) show that, for inner diameters of 2.0 and $1.5 \mathrm{~mm}$, when the working fluid was changed from R123 to ethanol and water, or when the latent heat of evaporation increased, heat flux increased and thermal resistance decreased.

Previous studies indicated that internal flow pattern in VCLOHP consisted of slug flow mixing with churn flow inside the evaporator section, the working fluid circulated in one direction $[3,18-20]$. Churn flow has a vapor portion greater than the liquid, and the CLOHP transfers heat mainly by the latent heat rather than sensible heat. Heat transfer is higher compared to only single-phase forced convection [3]. This is the reason why heat flux increases as the latent heat of evaporation increases, as observed when using inner diameters of 2.0 and $1.5 \mathrm{~mm}$.

By contrast, for $1.0 \mathrm{~mm}$ inner diameter, ethanol and R123 showed higher heat flux than water, as shown in Figure 4(c). This outcome can be explained that water has high surface tension and a smaller inner diameter leads to higher frictional pressure flow resistance. Thus, the VCLOHP with water as working fluid requires heat more than R123 and ethanol to move the fluid from the hot region to the cold region of the heat pipe.

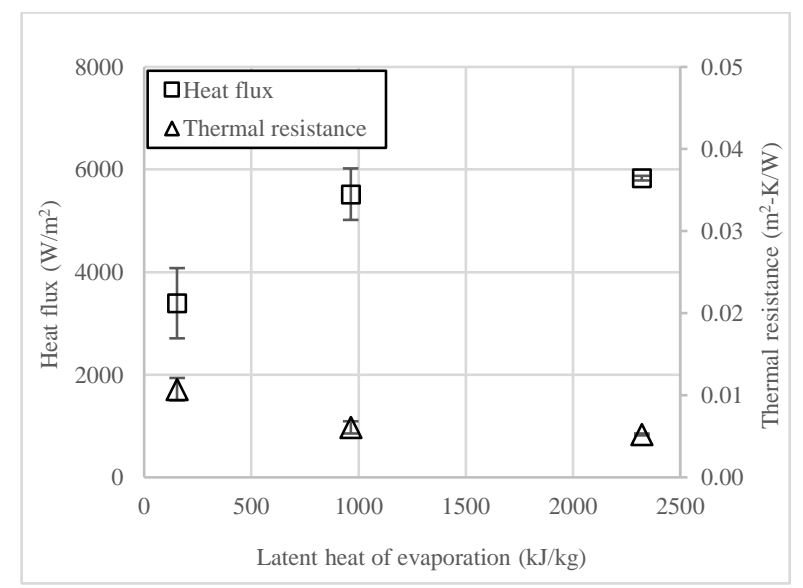

(a)

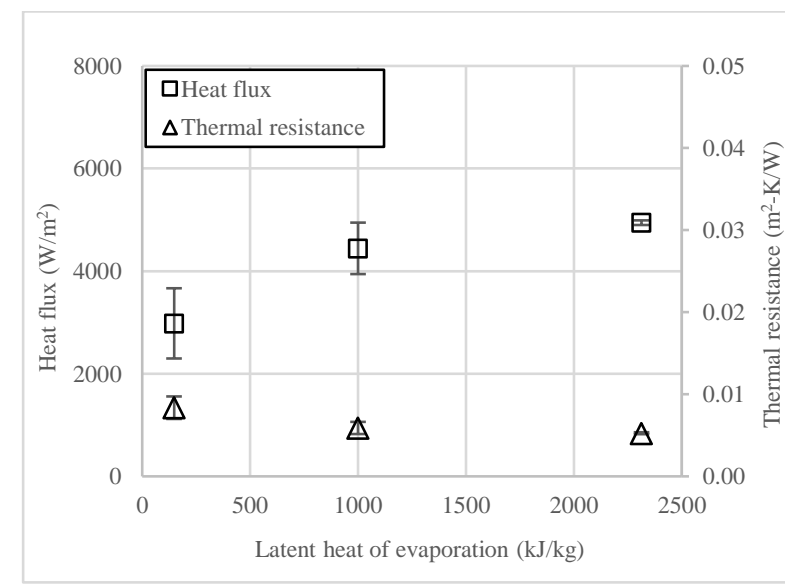

(b)

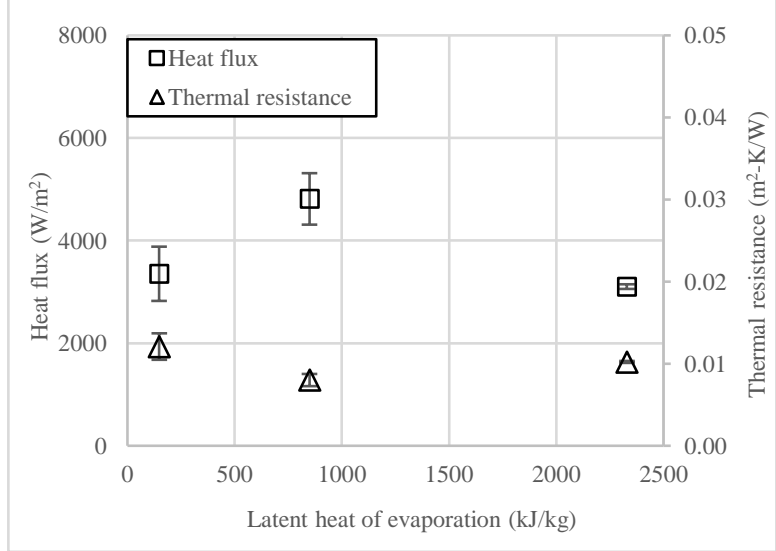

(c)

Fig. 4. Effect of latent heat of evaporation; (a) Inner diameter of $2.0 \mathrm{~mm}$, (b) Inner diameter of $1.5 \mathrm{~mm}$, (c) Inner diameter of $1.0 \mathrm{~mm}$ 


\section{Conclusions}

This paper presents the effects of inner diameter and working fluids on a VCLOHP w/DHS thermal performance. The notable results are concluded as follows

i. The thermal performance increased with the inner diameter. This outcome is because, with a larger inner diameter, vapor plugs evaporate in the evaporator section and, consequently, flow towards the condenser section more continual with a higher quantity of working fluid. Thus, the VCLOHP w/DHS can transfer more heat; thermal performance increases.

ii. When the latent heat of evaporation increased, the thermal performance also increased since a working fluid with higher latent heat can transfer more heat from the hot region to the cold region of the heat pipe.

\section{Acknowledgement}

The author would like to thank the Department of Mechanical Engineering, Faculty of Engineering and Industrial Technology, Silpakorn University for supporting this research.

\section{References}

[1] Akachi, Hisateru, F. Polášek, and P. Štulc. "Pulsating heat pipes." In Proceedings 5th International Heat Pipe Symposium, Melbourne, Australia (1996).

[2] Maezawa, S., K. Y. Gi, A. Minamisawa, and H. Akachi. "Thermal performance of capillary tube thermosyphon." In Proc. 9th Int. Heat Pipe Conf, vol. 2, pp. 791-795. 1995.

[3] Verma, Bhawna, Vijay Lakshmi Yadav, and Kaushal Kumar Srivastava. "Experimental Studies on Thermal Performance of a Pulsating Heat Pipe with Methanol/DI Water." Journal of Electronics Cooling and Thermal Control 3, no. 1 (2013): 27-34. https://doi.org/10.4236/jectc.2013.31004

[4] Charoensawan, Piyanun, Sameer Khandekar, Manfred Groll, and Pradit Terdtoon. "Closed loop pulsating heat pipes: Part A: parametric experimental investigations." Applied Thermal Engineering 23, no. 16 (2003): $2009-2020$. https://doi.org/10.1016/S1359-4311(03)00159-5

[5] Yang, Honghai, S. Khandekar, and M. Groll. "Operational limit of closed loop pulsating heat pipes." Applied Thermal Engineering 28, no. 1 (2008): 49-59. https://doi.org/10.1016/i.applthermaleng.2007.01.033

[6] Charoensawan, Piyanun, and Pradit Terdtoon. "Thermal performance of horizontal closed-loop oscillating heat pipes." Applied Thermal Engineering 28, no. 5-6 $\quad$ (2008): $460-466$. https://doi.org/10.1016/i.applthermaleng.2007.05.007

[7] Li, Jia, and Li Yan. "Experimental research on heat transfer of pulsating heat pipe." Journal of Thermal Science 17, no. 2 (2008): 181-185. https://doi.org/10.1007/s11630-008-0181-z

[8] Jahan, Suchana Akter, Mohammad Ali, and Md Quamrul Islam. "Effect of inclination angles on heat transfer characteristics of a closed loop pulsating heat pipe (CLPHP)." Procedia Engineering 56 (2013): 82-87. https://doi.org/10.1016/i.proeng.2013.03.092

[9] Pachghare, Pramod R., and Ashish M. Mahalle. "Effect of pure and binary fluids on closed loop pulsating heat pipe thermal performance." Procedia Engineering 51 (2013): 624-629. https://doi.org/10.1016/i.proeng.2013.01.088

[10] Qu, Jian, and Qian Wang. "Experimental study on the thermal performance of vertical closed-loop oscillating heat pipes and correlation modeling." Applied Energy 112 (2013): 1154-1160. https://doi.org/10.1016/i.apenergy.2013.02.030

[11] Barua, Himel, Mohammad Ali, Md Nuruzzaman, M. Quamrul Islam, and Chowdhury M. Feroz. "Effect of filling ratio on heat transfer characteristics and performance of a closed loop pulsating heat pipe." Procedia Engineering 56 (2013): 88-95. https://doi.org/10.1016/j.proeng.2013.03.093

[12] Xue, Zhihu, and Wei Qu. "Experimental study on effect of inclination angles to ammonia pulsating heat pipe." Chinese Journal of Aeronautics 27, no. 5 (2014): 1122-1127. https://doi.org/10.1016/i.cja.2014.08.004

[13] Babu, E. R., and GV Gnanendra Reddy. "Effect of working fluid and filling ratio on performance of a closed loop pulsating heat pipe." Journal of Engineering Science and Technology 11, no. 6 (2016): 872-880.

[14] Patel, Vipul M., and Hemantkumar B. Mehta. "Influence of working fluids on startup mechanism and thermal performance of a closed loop pulsating heat pipe." Applied Thermal Engineering 110 (2017): 1568-1577. https://doi.org/10.1016/j.applthermaleng.2016.09.017 
[15] Zufar, Muhammad, Prem Gunnasegaran, Khai Ching Ng, and Hemantkumar B. Mehta. "Evaluation of the thermal performance of hybrid nanofluids in pulsating heat pipe." CFD Letters 11, no. 11 (2019): 13-24.

[16] Islam, Fabliha, Fahima Akhter, Sifat bin Haider, and Mohammad Ali. "Effect of inner diameter on the thermal performance of closed loop pulsating heat pipe." In Proceedings of 102nd The IIER International Conference, Singapore, May 2nd-3rd, 2017, pp. 5-8. 2017.

[17] Kammuang-Lue, Niti, Phrut Sakulchangsatjatai, and Pradit Terdtoon. "Effect of working fluids and internal diameters on thermal performance of vertical and horizontal closed-loop pulsating heat pipes with multiple heat sources." Thermal Science 20, no. 1 (2016): 77-87. https://doi.org/10.2298/TSCI140904141K

[18] Khandekar, Sameer, Piyanun Charoensawan, Manfred Groll, and Pradit Terdtoon. "Closed loop pulsating heat pipes Part B: visualization and semi-empirical modeling." Applied Thermal Engineering 23, no. 16 (2003): 2021-2033. https://doi.org/10.1016/S1359-4311(03)00168-6

[19] Kammuang-Lue, Niti, Phrut Sakulchangsatjatai, Pradit Terdtoon, and D. Joseph Mook. "Correlation to predict the maximum heat flux of a vertical closed-loop pulsating heat pipe." Heat Transfer Engineering 30, no. 12 (2009): 961 972. https://doi.org/10.1080/01457630902837442

[20] Karthikeyan, V. K., Sameer Khandekar, B. C. Pillai, and Pavan K. Sharma. "Infrared thermography of a pulsating heat pipe: Flow regimes and multiple steady states." Applied Thermal Engineering 62, no. 2 (2014): 470-480. https://doi.org/10.1016/i.applthermaleng.2013.09.041 